"What do we do to ration the

available funds, or rather the

services that those funds will buy?"

\title{
Wouldn't it be a lovely Christmas present if...
}

A first glance at the title suggests that it might be the prompt to the beginning of a cosy seasonal story or perhaps the tag line for a radio game show, 'you've got one minute on, wouldn't it be a lovely Christmas present if..., starting now'. It could be either, or both, but it does in fact have a serious purpose even if some imagination might be involved and more than a pinch of creativity would be desirable.

So, let's plunge into the festive wish list. Wouldn't it be a lovely Christmas present if politicians were honest, or at least, more honest? I understand if you are now thinking that this is a fairy story but stay with me a while longer as the yuletide log glows brighter in the grate. It is quite apparent to all of us in dentistry that the money made available by the government, and indeed successive governments, is insufficient to purchase the very laudable resources that would enable a universal service that is free at the point of delivery for all UK citizens. You don't need to write an editorial to know that. We all know it is a fact of life and has been since shortly after the NHS dental service started over fifty years ago. I suspect even politicians could be made to 'admit' that one.

Getting a notion of the spectrum is often a valuable exercise and to do that we need to travel to the other end of the question. Is it possible to pay for any dental services with the money made available? Obviously this is just as easy to answer, and positively, yes there is a substantial amount of money available.

Now here comes the part where we need the honesty. If the sum isn't available for all that is wanted but it is available for some of what is wanted, how do we bridge the gap? What do we do to ration the available funds, or rather the services that those funds will buy? Under previous NHS dental agreements the annual sums were (ever so slightly) elastic, something that the Treasury loathed. There is nothing a financial person hates more than not knowing what something will cost; it spoils all their careful calculations. Based on the fee for item of service system it was impossible to predict exactly how many restorations would be placed, teeth extracted, dentures made and so forth in any given year. Weighting of the fees helped to guide the estimate but it was a fairly crude governor on a fairly blunt tool. From a politician's viewpoint though it provided just enough leeway to allow the claim that services and treatment should theoretically be available to all.

The new contract and the new systems have no such slack, no little bits at the margin to allow daydreaming. The sum of money available is capped, decided, final. The Treasury must be thrilled. At last; certainty. Not only that but the total sum has been chopped into manageable sized chunks and parcelled off to decentralised decision makers. Whether this is the really clever part or just a rather convenient by-product of the system we each have to decide for ourselves but the effect, at least in the early stages, was to make the dentist the person who seemed to be 'rationing' what was available. Once the stock of UDAs (Units of Dental Activity) was used up then there were no more and it was the dentist who, apparently, was not providing them anymore.

But the perception has not lasted long. The press, patients and society in general are beginning to see through if not the complexities of the contract then at least the system that lies beneath it and the resultant limitation on service provision.

So, as the ashes start to glow in the grate, I return to my original fancy. Instead of pretending that the NHS can be all things to all people how much more honest would it be to come up with an openly discussed, negotiated and agreed system? A system that both patients and dentists understood and which defined perhaps a core service, perhaps a means-tested scheme, perhaps a much larger sum paid to public dental health but which made it clear what, as a society, we had decided we could afford and would afford to pay for oral health services and what would be available as a result. Would you vote for a politician who made that clear? I suspect I would and I suspect many others would too, as much for the refreshing openness as for the policy itself.

So, wouldn't it be a lovely Christmas present if...and wouldn't it be an even better Boxing Day treat if...?

Stephen Hancocks OBE Editor-in-Chief

DOI: $10.1038 / b d j .2007 .1158$ 